\title{
Regorafenib Combined with Other Systemic Therapies: Exploring Promising Therapeutic Combinations in $\mathrm{HCC}$
}

\author{
Alessandro Granito $\mathbb{D}^{1,2}$ \\ Sara Marinelli' \\ Antonella Forgione $e^{1,2}$ \\ Matteo Renzulli ${ }^{3}$ \\ Francesca Benevento ${ }^{2}$ \\ Fabio Piscaglia $\mathbb{I D}^{1,2}$ \\ Francesco Tovoli ${ }^{1,2}$ \\ 'Division of Internal Medicine, \\ Hepatobiliary and Immunoallergic \\ Diseases, IRCCS Azienda Ospedaliero- \\ Universitaria di Bologna, Bologna, Italy; \\ ${ }^{2}$ Department of Medical and Surgical \\ Sciences, University of Bologna, Bologna, \\ Italy; ${ }^{3}$ Radiology Unit, IRCCS Azienda \\ Ospedaliero-Universitaria di Bologna, \\ Bologna, Italy
}

\begin{abstract}
Regorafenib was the first drug to demonstrate a survival benefit as a second-line agent after sorafenib failure in patients with unresectable hepatocellular carcinoma (HCC). Recent studies have shown that its mechanism of action is not only limited to its very broad spectrum of inhibition of angiogenesis, tumor proliferation, spread, and metastasis, but also to its immunomodulatory properties that have favorable effects on the very intricate role that the tumor microenvironment plays in carcinogenesis and tumor growth. In this review, we discuss rationale and evidence supporting regorafenib efficacy in HCC and that led to its approval as a second-line treatment, after sorafenib failure. We also discuss the evidence from clinical practice studies that confirm the results previously achieved in clinical trials. Finally, we analyze the potential role of regorafenib in emerging combined treatment approach with immunotherapy strategies using immune checkpoint blockade and its potential extension to patient categories not included in the registrative study.
\end{abstract}

Keywords: hepatocellular carcinoma, HCC, regorafenib, tyrosine kinase inhibitor, TKI, systemic treatment, combination treatment

\section{Introduction}

Hepatocellular carcinoma ( $\mathrm{HCC}$ ) is the fifth most common cancer and the third most frequent cause of cancer death worldwide, with 905.677 new cases and 830.180 deaths in 2020 which are responsible for $8.3 \%$ of all cancers. ${ }^{1}$

Hepatocellular carcinoma (HCC) accounts for nearly $90 \%$ of primary liver cancers and is a leading world health problem. The incidence of HCC increases dramatically with age in all populations, achieving a peak at age 70 , and is increasing in most countries being the dominant cause of mortality in cirrhotic patients. ${ }^{2-4}$

Globally, chronic viral hepatitis and alcoholic liver disease are the leading risk factors for HCC development, although in high-income areas non-alcoholic fatty liver disease (NAFLD) linked to HCC is increasing due to the increasing prevalence of metabolic disorders. ${ }^{5-7}$

In contrast, vaccination and treatment for hepatitis B virus (HBV) infection, prevention campaigns for sexual and iatrogenic transmission of HBV and hepatitis $\mathrm{C}$ virus (HCV), and the introduction of effective $\mathrm{HCV}$ antiviral agents are reducing the burden of chronic viral liver disease. ${ }^{8-11}$

Since 2007, for HCC patients with preserved liver function and advanced or intermediate Barcelona Clinic Liver Cancer (BCLC) stage, unsuitable for
Correspondence: Alessandro Granito IRCCS Azienda Ospedaliero-Universitaria di Bologna, via Albertoni I5, Bologna, Italy Email alessandro.granito@unibo.it 
locoregional treatment, the multikinase inhibitor (MKI) sorafenib has been considered the standard of care worldwide. ${ }^{12}$ After a decade of unsatisfactory results, other agents have been approved as a first-line alternative to sorafenib, or in a second-line setting, after sorafenib failure. ${ }^{13-17}$ Besides, immune checkpoint inhibitors (ICIs) targeting the programmed cell death receptor-1 (PD-1), anti-programmed death-ligand 1 (PD-L1), and anticytotoxic $\mathrm{T}$ lymphocyte associated antigen 4 (CTLA-4) have recently received accelerated approval. ${ }^{14,18-20}$

In 2016 the randomized, placebo-controlled, Phase III RESORCE trial was the first demonstrating that systemic treatment with regorafenib in patients experiencing failure of first-line therapy with sorafenib resulted in a significant increase in OS in the treatment arm compared to the placebo arm [10.6 versus 7.8 months, HR 0.63 (95\% CI $0.50-0.79$ ), $\mathrm{p}<0.0001$, after a decade of failed clinical trials investigating a wide range of drugs tested for second-line treatment. ${ }^{15}$

Since registration and the start of its use in clinical practice, real-life experiences have also been reported. ${ }^{21}$ Also, recent developments in the systemic treatment of HCC have opened new possible scenarios in the potential use of regorafenib in combination with other agents or new options for its sequential use. ${ }^{22,23}$
In this review, we examine the main preclinical and clinical results of studies evaluating regorafenib for the treatment of HCC patients and discuss the rationale for its possible use in combination treatment with other agents as well as potential options in a sequential treatment strategy.

\section{Mechanism of Action}

Regorafenib (chemical name 4-(4-(3-(4-Chloro- 3-(trifluoromethyl) phenyl) ureido)- 3-fluorophenoxy)$\mathrm{N}$-methylpicolinamide) is a small molecule inhibitor and belongs to the group of biaryl urea compounds. Regorafenib is an orally available multitargeted tyrosine kinase inhibitor (TKI) that was developed following a discovery program aimed at the optimization of the potency of sorafenib, from whom it differs only by the addition of a fluorine atom in the center phenyl ring (Figure 1). ${ }^{24}$

TKIs are a class of agents involved in the activation of a broad range of proteins via phosphorylation. TKIs bind to the active site of tyrosine kinases, thereby hindering phosphorylation and inhibiting downstream signal transduction of a variety of growth factors. By blocking key tyrosine kinase pathways in tumors, such as the vascular endothelial growth factor receptor (VEGFR), platelet-derived growth

\section{Sorafenib}<smiles>CNC(=O)c1cc(Oc2ccc(NC(=O)Nc3ccc(Cl)c(C(F)(F)F)c3)cc2)ccn1</smiles>

\section{Regorafenib}<smiles>CNC(=O)c1cc(Oc2ccc(NC(=O)Nc3ccc(Cl)c(C(F)(F)F)c3)c(F)c2)ccn1</smiles>

Figure I Similarly to sorafenib, regorafenib is a bi-aryl urea class of drug. The sole difference between sorafenib and regorafenib is the presence of a fluorine atom (red arrow) in the latter. Due to a mechanism that has not yet been fully defined, this one unique difference produces a wider kinase inhibitory profile. In complement to the targets that are inhibited by sorafenib, regorafenib also blocks the signaling pathway of Tie2, the receptor for angiopoietin-2, a pro-angiogenic cytokine. 
factor (PDGFR), and epidermal growth factor receptor 2 (EGFR), they inhibit tumor growth. TKIs differ in their spectrum of inhibition, which can also simultaneously hit multiple targets and thus inhibit tumorigenesis differently. ${ }^{25}$

Preclinical studies have shown that regorafenib targets kinases involved in signaling pathways driving tumorigenesis, cancer progression, and tumor microenvironment maintenance. These kinases are isoforms of rapidly accelerated fibrosarcoma (RAF) RAF-1, B-RAF, B-RAFV600E (a mutant B-RAF isoform), VEGFR 1, 2 and 3, the oncogenic kinases KIT and RET, angiopoietin 1 receptor (TIE2), platelet-derived growth factor receptor (PDGFR), fibroblast growth receptors (FGFRs) 1 and 2 (Figure 2). ${ }^{24,26-31}$

Thus, the dual blockade of VEGF receptors and TIE2 can lead to an obvious and unique enhancement of the effect of tumor vessel reduction.

Among the approved systemic therapies for HCC with anti-angiogenic effects, regorafenib blocks a broader range of targets (Table 1).

There are also findings suggesting regorafenib's antiimmunosuppressive property and promotion of anti-tumor immunity. ${ }^{32}$ Regorafenib has the important effect of enhancing anti-tumor immunity via macrophage modulation and increase proliferation and activation of $\mathrm{CD} 8+$ $\mathrm{T}$ cells (Figure 2). Tumor-associated macrophages (TAMs), a key element of leukocyte infiltration, enhance tumor cell growth, development and migration. ${ }^{32,33}$ The role of TAMs in carcinogenesis is well-documented in several tumor types, including HCC. ${ }^{34,35}$

Regorafenib also impairs tumor immunity by inhibiting the colony-stimulating factor 1 receptor CSF1R which is critical for macrophage differentiation and survival and causes a reduction in tumor infiltration of macrophages. ${ }^{29,31,36}$

In agreement, regorafenib has been shown to decrease the infiltration of TAM, which is crucial for angiogenesis and metastatic spreading, and reverts their polarization from M2 pro-tumor phenotype to M1 tumor growthinhibiting phenotype. ${ }^{29,32}$

Recently, the synergistic relationship between regorafenib and natural killer (NK) cells has been reported. The binding of NKG2D receptors on the surface of NK cells and NKG2DL expressed in tumor cells leads to the activation of NK cells elimination of tumor cells. However, tumor cells utilize various mechanisms to evade the NKG2D receptor/NKG2DL mediated immune clearance. $^{37}$ Tai and colleagues demonstrated that Regorafenib induces STAT3 signaling pathway inhibition, resulting in enhanced NK cell cytolytic activity via upregulation of the NKG2D ligand and assisting recognition of HCC cells by NK cells and ultimately HCC cell apoptosis. $^{38}$

Lastly, it has been reported that long-term regorafenib therapy has been also demonstrated to lower angiogenesis and also to be beneficial to portal hypertension, and acute administration improves portal hemodynamics, indicating

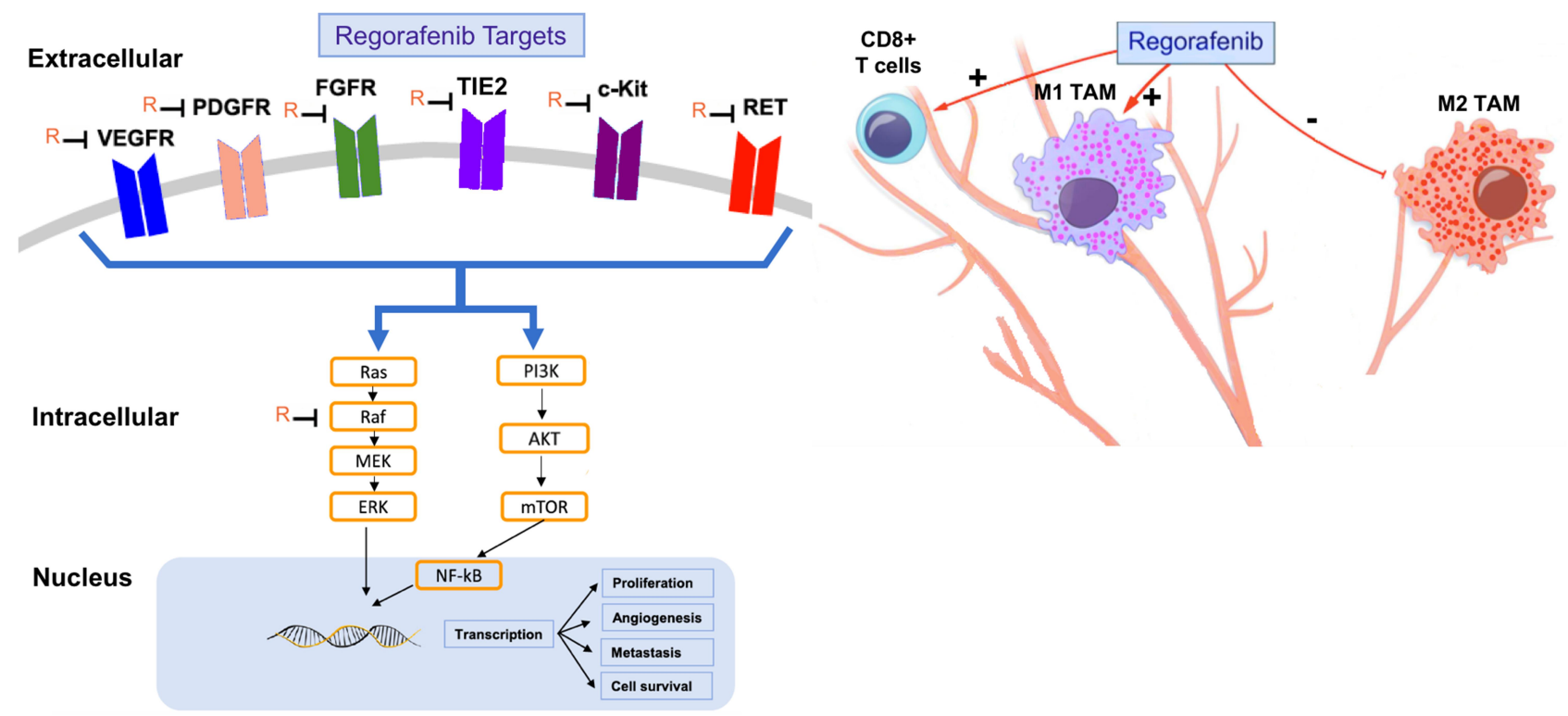

Figure 2 Regorafenib is able to inhibit several molecular pathways by targeting angiogenic, stromal, oncogenic and intracellular kinases. Regorafenib induces MI macrophage polarization and increases CD8+ T cells proliferation and activation thus also acting on the tumor microenvironment and immunosuppression. 
Table I Target Structures of Systemic Therapies with Antiangiogenic Effects

\begin{tabular}{|c|c|c|c|c|c|c|c|c|c|c|c|c|c|}
\hline \multirow[t]{2}{*}{ Line } & \multirow[t]{2}{*}{ Drug } & \multirow{2}{*}{$\begin{array}{c}\text { Drug } \\
\text { Category }\end{array}$} & \multicolumn{11}{|c|}{ Cellular Targets } \\
\hline & & & VEGFR I & VEGFR2 & VEGFR3 & PDGFR & RAF & FGFR & KIT & RET & $\begin{array}{c}\text { TIE- } \\
2\end{array}$ & MET & AXL \\
\hline Ist & Sorafenib & TKI & $\bullet$ & $\bullet$ & $\bullet$ & $\bullet$ & $\bullet$ & & $\bullet$ & $\bullet$ & & & \\
\hline Ist & Lenvatinib & TKI & $\bullet$ & $\bullet$ & 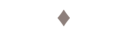 & $\bullet$ & & $\bullet$ & $\bullet$ & 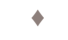 & & & \\
\hline 2nd & Regorafenib & TKI & $\bullet$ & $\bullet$ & $\bullet$ & $\bullet$ & $\bullet$ & $\bullet$ & $\bullet$ & $\bullet$ & $\bullet$ & & \\
\hline 2nd & Cabozantinib & TKI & & $\bullet$ & & & & & $\bullet$ & $\bullet$ & $\bullet$ & $\bullet$ & 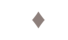 \\
\hline 2nd & Ramucirumab & TKI & & $\bullet$ & & & & & & & & & \\
\hline
\end{tabular}

Note: Among the approved systemic therapies for HCC with anti-angiogenic effects, regorafenib displays the broadest spectrum of inhibited target receptors.

that it may be particularly beneficial to patients with portal hypertension and maintained hepatic function. ${ }^{39}$

As such, regorafenib's broad spectrum of kinase inhibition, together with its immunomodulatory effects, may explain its established and emerging clinical activity in various tumor types and have offered a rationale for supporting clinical trials to investigate the development of a combination strategy with immune checkpoint inhibitors. $^{40-42}$

Regorafenib is metabolized by UGT1A9 and CYP3A4 enzymes to two active metabolites M-5 (demethylated N-oxide) and M-2 (N-oxide). ${ }^{43}$

CYP enzymes may be inhibited or induced by the coadministration of agents that interact with the same enzymes. Co-administration of regorafenib with a strong CYP3A4 inhibitor might increase the regorafenib serum area under the curve (AUC). This could result in a potential enhancement of drug toxicity. On the contrary, co-administration of regorafenib with a significant CYP3A4 inducer would lead to a regorafenib decline in the serum AUC levels and a potential reduction in efficacy. The M-5 and M-2 regorafenib metabolites also influence CYP isoenzymes having been shown capable of inhibiting CYP2C9 (the enzyme responsible for metabolizing warfarin), CYP2B6, CYP3A4 and CYP2C8 enzymes. ${ }^{44}$

Table 2 lists the agents potentially interacting with regorafenib and the effects of such interactions. In view of the potential pharmacological interactions, drug compatibility would have to be checked in all patients before starting regorafenib treatment.

\section{Established Activity of Regorafenib in HCC}

In preclinical studies, regorafenib was confirmed to be a strong inhibitor of Raf-1 and various receptor tyrosine kinases implicated in neovascularization and tumor
Table 2 Major Drug Interactions with Regorafenib

\begin{tabular}{|c|c|c|c|}
\hline $\begin{array}{l}\text { Inducers of } \\
\text { CYP3A4* }\end{array}$ & $\begin{array}{c}\text { Inhibitors of } \\
\text { CYP3A4 }\end{array}$ & $\begin{array}{l}\text { CYP2C9 } \\
\text { Inhibition }^{\#}\end{array}$ & $\begin{array}{l}\text { UGTIAI } \\
\text { Inhibitor }^{\&}\end{array}$ \\
\hline $\begin{array}{l}\text { - } \text { Carbamazepine } \\
\text { - Isoniazid } \\
\text { - Phenobarbital } \\
\text { - Phenytoin/ } \\
\text { - fosphenytoin } \\
\text { - Rifampin } \\
\text { - St. John's wort } \\
\text { (Hypericum } \\
\text { perforatum) }\end{array}$ & $\begin{array}{l}\text { - Boceprevir } \\
\text { - Clarithromycin } \\
\text { - Conivaptan } \\
\text { - Grapefruit juice } \\
\text { - Ketoconazole } \\
\text { - Indinavir } \\
\text { - Itraconazole } \\
\text { - Nefazodone } \\
\text { - Nelfinavir } \\
\text { - Posaconazole } \\
\text { - Ritonavir } \\
\text { - Saquinavir } \\
\text { - Telaprevir } \\
\text { - Telithromycin } \\
\text { - Voriconazole }\end{array}$ & - Warfarin & - Irinotecan \\
\hline
\end{tabular}

Notes: *Inducers of CYP3A4 may decrease exposure to regorafenib and exposure to M-2 and M-5 metabolites may increase. Inhibitors of CYP3A4 may increase exposure to regorafenib and exposure to $\mathrm{M}-2$ and $\mathrm{M}-5$ metabolites may decrease. ${ }^{\#}$ Regorafenib inhibits CYP2C9; concomitant administration of drugs that are CYP2C9 substrates may result in increased exposure of that drug. ${ }^{~}$ Regorafenib is a UGTIAI inhibitor: concomitant use with irinotecan may result in increased irinotecan exposure.

progression, such as VEGFR-1-2-3, PDGFR, c-KIT, and FGFR. In xenograft models, this agent resulted in tumor growth inhibition of extracellular signal-regulated kinase phosphorylation, which could be revealed by an expressive decrease in microvessels density inside the tumor area. ${ }^{31,45}$

A Phase 2 study with 36 patients with HCC displayed both acceptable tolerability and proof of antitumor activity, with a median OS of 13.8 months and median TTP of 4.3 months. $^{46}$

These results led to the conception of the RESORCE study, a Phase 3 placebo-controlled trial, which included patients who had progressed on sorafenib but were tolerating $\geq 400 \mathrm{mg} / \mathrm{d}$ for $\geq 20$ of the last 28 days of treatment. ${ }^{15}$ The last dose of sorafenib had to have been received 
within the last 10 weeks prior to randomization, and 2 weeks washout from the last dose of sorafenib was required before starting regorafenib, and exclusion criteria included discontinuation of sorafenib due to toxicity. The trial was carried out in 152 centers across 21 different countries and four continents. Participants were assigned randomly $(2: 1)$ to $160 \mathrm{mg}$ oral regorafenib or placebo once daily for 3 weeks followed by 1-week off. A total of 4 weeks constituted one full treatment cycle. All patients received the best supportive care.

The primary endpoint of the trial was overall survival time (time from randomization to death) and analyzed by intention to treat. The secondary endpoints were TTP, PFS, objective response rate ( $\mathrm{CR}$ or $\mathrm{PR})$, and disease control rate (CR, $P R$, or SD maintained for $\geq 6$ weeks) as estimated by the investigators applying mRECIST and RECIST 1.1.

Patients were stratified by geographical region (Asia vs the rest of the world), the presence of macrovascular invasion (yes vs no), presence of extra-hepatic disease (yes vs no), $\alpha$-fetoprotein concentration ( $<400$ vs $>400$ $\mathrm{ng} / \mathrm{mL}$ ), and Eastern Cooperative Oncology Group performance status ( 0 vs 1 ). Following the screening of 843 patients, 573 were enrolled and randomized (379 to the regorafenib arm and 194 to the placebo arm).

A total of 216 patients were from Asia. The median treatment duration on sorafenib before commencing regorafenib was 7.8 months (IQR 4.2-14.5) in the regorafenib arm and 7.8 months (IQR: 4.4-14.7) in the placebo arm. The median time on regorafenib in this study was 3.6 months (IQR: 1.6-7.6) and 1.9 months (IQR: 1.4-3.9) on placebo. The mean daily regorafenib dose was $144.1 \mathrm{mg}$. With major relevance, a systemic therapy yielded a significantly higher $\mathrm{OS}$ in the second-line setting, with a 10.6 months median OS (95\% CI: 9.1-12.1) on regorafenib compared with 7.8 months $(6.3-8.8)$ for the placebo (HR: 0.63 ; 95\% CI: $0.50-0.79 ; p<0.0001$ ) with a $37 \%$ reduction in the risk of death. Median PFS was also significantly improved in the regorafenib group at 3.1 months (95\% CI: 2.8-4.2) compared with 1.5 (1.4-1.6) months with the placebo group. This was a $54 \%$ reduction in the risk of progression or death (HR: 0.46 ; 95\% CI: 0.37-0.56; $\mathrm{p}<0.0001)$. The median TTP in the regorafenib arm was 3.2 months (2.9-4.2 95\% CI) with regorafenib compared with 1.5 (1.4-1.6) months in the placebo arm (HR: 0.44; 95\% CI: $0.36-0.55 ; \mathrm{p}<0.0001)$. A total of $11 \%$ of patients treated with regorafenib compared with $4 \%$ in the placebo arm attained an objective response $(\mathrm{p}=0.0047)$. Two patients $(1 \%)$ in the regorafenib arm versus zero patients in the placebo arm achieved a CR.

The rate of alpha-fetoprotein (AFP) response, defined as a $\geq 20 \%$ decrease in AFP from baseline at the start of cycle 3, was higher in patients treated with regorafenib than in those who received placebo.

The toxicity profile of regorafenib was similar to other TKIs, especially sorafenib. In the early phase studies, dose-limiting toxicities included bone marrow suppression and gastrointestinal toxicities. ${ }^{31,42,44,45}$ In the subsequent Phase II trial of patients with $\mathrm{HCC}, 58 \%$ of patients experienced a grade 3 or higher adverse event (AE). ${ }^{46}$ These included fatigue $(17 \%)$, hand-foot skin reaction $(14 \%)$, and diarrhea (6\%). A total of $19 \%$ of patients stopped treatment due to AEs that were deemed treatmentrelated as per investigator opinion. In the following Phase III RESORCE study, AEs were reported in all patients treated with regorafenib (100\%) and 179 of 193 patients were receiving placebo $(93 \%){ }^{15}$ The most frequent clinically relevant grade 3 or 4 treatment-emergent adverse events (TEAEs) were hypertension (15\%), hand-foot skin reaction (HFSR) (13\%), fatigue (9\%), and diarrhea $(3 \%)$. A total of $10 \%$ experienced a regorafenib-related serious AE and seven deaths (2\%) were attributed to the study drug compared with $2 \%$ in the placebo group.

The only drug-related deaths due to liver failure were seen in the placebo group. A total of $6 \%$ of patients in the regorafenib treatment arm had grade 3 or higher TE bleeding events compared with $8 \%$ in the placebo arm.

A total of $255(68 \%)$ of 374 patients in the regorafenib arm had dose interruptions or reductions due to AEs compared with $60(31 \%)$ of 193 patients in the placebo arm.

Overall, regorafenib was well tolerated. Drug-related AEs led to dose interruptions or reductions in 202 (54\%) patients in the regorafenib arm and $20(10 \%)$ in the placebo arm, discontinuation due to a treatment-related AEs was relatively low at $39(10 \%)$ in the regorafenib arm compared with $7(4 \%)$ in the placebo arm.

The most common AEs leading to treatment discontinuation more frequently seen with regorafenib were i) increase in the liver enzyme aspartate transaminase (AST) (8 [2\%] of 374 patients vs 3 [2\%] in the placebo group), ii) hand-foot skin reaction (7 [2\%] vs none), and iii) an increase in alanine transaminase (ALT) (4 [1\%] vs none).

Further subanalyses of the RESORCE study have been performed and showed that I) a longer survival follow-up almost 1 year after the primary analysis confirmed the primary OS results; ${ }^{47}$ II) by comparing tumor response 
and progression in the RESORCE trial by mRECIST and RECIST 1.1, although a slightly higher response rate was observed using mRECIST criteria, rates of PFS, TTP, and disease control were not different when assessed by investigators using mRECIST or RECIST $1.1 ;^{48,49}$ III) in an exploratory analysis, aimed at validating concept of progression profile in a global cohort of previously sorafenib treated patients and assessing the impact of regorafenib on survival by looking at previous progression, regorafenib provides an OS benefit regardless of progression pattern $;^{50}$ IV) in a post-hoc exploratory analysis, patients developing HFSR under regorafenib tended to have improved OS (Median OS, months 14.1 months [95\% CI 11.7, 16.5] versus $6.6[5.0,8.5])$, as was previously shown for sorafenib. 51,52

Finally, an exploratory analysis of the RESORCE study reported that patients who received the sorafenibregorafenib sequence achieved a never-beforedemonstrated outcome, with a median OS of 26 months. ${ }^{53}$

Also, the analysis showed that regorafenib treatment resulted in a clinical benefit regardless of the sorafenib last dose or TTP on sorafenib.

\section{Real-Life Clinical Practice of Regorafenib Treatment in HCC}

Since the approval of regorafenib in 2017, clinical practice studies have reported results, which are however still limited, on the safety and efficacy profile of regorafenib in real-life experience. ${ }^{54-57}$

REFINE (NCT03289273) is an ongoing observational study that recruited patients with $\mathrm{HCC}$ for whom a decision to treat with regorafenib was made by the treating physician before enrollment, according to the local health authority approved label. ${ }^{54}$

The findings from the interim analysis carried out after the first 500 enrolled patients were presented during the 2020 International Liver Cancer Association (ILCA). ${ }^{55}$

REFINE had a broader patient population compared with RESORCE, which reflects the less stringent inclusion criteria of the real-world study. Most patients (67\%) had Child-Pugh class A liver function; $11 \%$ and $1 \%$ had Child-Pugh class $\mathrm{B}$ and $\mathrm{C}$ liver function, respectively (the Child-Pugh score was missing or not evaluable in $21 \%$ of patients).

The proportions of patients with Eastern Cooperative Oncology Group performance status (ECOG PS) 0, 1, and 2-4 were $42 \%, 40 \%$, and 5\%, respectively (the ECOG PS was missing or not evaluable in $13 \%$ of patients). Most patients $(98 \% ; n=490)$ had received prior systemic therapy; 97\% $\quad(n=482)$ had received prior sorafenib. Regorafenib was second-line treatment in $81 \%$ of patients $(n=403)$, third-line or higher in $17 \%(n=87)$, and first-line in $2 \%(n=8)$.

Of the 403 patients who received regorafenib secondline, 398 (99\%) had received prior sorafenib. Among all treated patients $(\mathrm{N}=498), 57 \%(\mathrm{n}=286)$ initiated regorafenib at a daily dose of $160 \mathrm{mg}, 13 \%(\mathrm{n}=63)$ at $120 \mathrm{mg}, 28 \%$ $(\mathrm{n}=141)$ at $80 \mathrm{mg}$, and $2 \%(\mathrm{n}=8)$ at $40 \mathrm{mg}$.

In the 482 patients who received sorafenib in any prior line of therapy, the median duration of prior sorafenib was 4.8 months (interquartile range 2.5-9.6), 45\% of patients $(\mathrm{n}=216)$ had a last daily sorafenib dose of $800 \mathrm{mg}, 8 \%$ of patients $(n=40)$ had an AE leading to sorafenib discontinuation (defined as sorafenib-intolerant patients) and, at study entry, the proportions of patients with Child-Pugh class $\mathrm{A}, \mathrm{B}$, and $\mathrm{C}$ liver disease were $67 \%, 12 \%$, and $1 \%$, respectively. Regarding safety, among all regorafenib treated patients ( $\mathrm{n}=498)$, the most frequent TEAEs (any grade) were HFSR (30\%), diarrhea (21\%), fatigue (16\%), and decreased appetite (14\%) while in sorafenib intolerant patients, the most frequent TEAEs (any grade) with regorafenib were diarrhea, HFSR, abdominal pain, and decreased appetite.

Investigators also evaluated the OS by Child-Pugh class and ALBI grade at study entry in the patients who had received sorafenib previously. The median OS was 16.0 months among the Child-Pugh class A group (95\% CI, 13.1-18.8) versus 8.0 months among the Child-Pugh class B group (95\% CI, 5.2-not evaluable [NE]). The median OS among those with ALBI grades 1, 2, and 3, respectively, was 19.6 months (95\% CI, 14.8-19.6), 10.5 (95\% CI, 8.7-16.0), and 3.1 months (95\% CI, 1.6-8.7).

Regorafenib confirmed survival benefit regardless of the rate of disease progression during the preceding treatment with sorafenib or since the last sorafenib dose in a retrospective study of safety and efficacy in Korean patients where data were consistent with those from the RESORCE trial. ${ }^{56}$

In a subsequent multicenter, retrospective analysis of 440 patients who received prior sorafenib and were treated with regorafenib as the second (69.3\%), third (26.1\%), and fourth to seventh $(4.5 \%)$ lines of therapy in nine tertiary referral hospitals in Korea, real-life clinical outcomes were consistent with the RESORCE trial results and regorafenib 
related HFSR resulted to be significantly associated with better OS. ${ }^{57}$

Interestingly, ICIs were given in 115 patients $(26.1 \%)$ prior to regorafenib and there were no differences in PFS and OS with regorafenib according to the prior use of ICIs.

A clinically relevant aspect emerging from some clinical practice studies is the importance of the patient's physical status and residual liver function after first-line failure. These parameters affect the rate of patients eligible for switching to second-line agents after radiologic progression with first-line sorafenib treatment.

A Canadian study characterized subsequent therapies received by HCC patients following sorafenib and determined the rate of patients eligible for novel therapies if strict eligibility criteria (SEC) (as defined in their respective trials) were used, compared to more liberal modified eligibility criteria (MEC, including Child-Pugh B7 and ECOG 2). ${ }^{58}$

A total of 730 patients were identified with 172 (23.6\%) receiving subsequent treatment (regorafenib, cabozantinib or ramucirumab). Patients receiving subsequent treatment had longer overall survival than patients who did not (12.1 versus 3.3 months; $p<0.001)$. Using SEC, only $13.1 \%$ of patients would be eligible for secondline treatment. Extending accessibility to patients meeting the MEC increased the eligibility rate to $31.7 \%$.

The highest ineligibility for regorafenib was determined by study-specific criteria, including intolerance to sorafenib (28\%).

Thus, the study showed that only a limited proportion of HCC real-world patients would be eligible for cabozantinib, regorafenib, or ramucirumab if SEC in clinical trials were followed, while more than double would be eligible if MEC were followed. Patients who received subsequent treatment had improved OS, irrespective of whether they encountered SEC or MEC.

A small Japanese retrospective study reported that in clinical practice only about $30 \%$ of patients refractory to first-line sorafenib therapy are eligible for second-line regorafenib treatment. ${ }^{59}$ The main reasons that patients could not be treated with regorafenib were their intolerance to sorafenib and deterioration of liver function.

This and other real-life studies highlight that to prolong the prognosis with the use of effective second-line agents, it is important to maintain liver function before and during both previous transarterial and first-line therapies. ${ }^{60}$

Adequate liver function reserve and ECOG performance status during treatment with sorafenib accounted for the efficacy and improved outcome of the following treatment. $^{60-62}$

This is substantiated by the finding that the novel biomarker of liver reserve function, albumin-bilirubin (ALBI) grade, was able to successfully detect regorafenib candidates and that a median OS of 15.6 months was obtained in the selected cohort compared to 6.8 months for non-candidates. ${ }^{63,64}$

Takada et al confirmed in a recent study that a more accurate estimation of liver function has emerged as an essential requirement in this setting. ${ }^{65}$ They showed that at the moment of failure of first-line sorafenib, the criteria for inclusion in the RESORCE study were not just the baseline ALBI score $(-2.33$; OR 2.5, $\mathrm{p}=0.01)$ but also the level of variation in liver function after four weeks of treatment with sorafenib $(<0.255$; OR 4.9, $\mathrm{p}<0.001)$.

Besides, Yukimoto et al showed that an ALBI score of -2.53 at the moment of sorafenib initiation was useful as a threshold value for the prediction of regorafenib eligibility following the failure of sorafenib. ${ }^{64}$

Similarly, Moriguchi et al showed that ALBI grade at the initiation of sorafenib therapy is a significant factor that contributed to the maintenance of Child-Pugh grade A and ECOG-PS $\leq 1$ upon sorafenib discontinuation and is a good indicator of the possibility of the introduction of second-line therapy after sorafenib for HCC. ${ }^{66}$

Accordingly, a recent small retrospective study suggests that regorafenib's clinical outcomes and increased frequency of severe adverse events would discourage its use in Child-Pugh B patients with ALBI grade $3{ }^{67}$

Since there are still no proven biomarkers in clinical practice to guide systemic therapy, a Japanese study aimed to evaluate relative dose intensity (RDI, defined as the ratio of administered dose to planned dose) and the association between RDI and OS in patients with unresectable HCC. ${ }^{68}$ Patients with first-month RDI $\geq 50 \%$ were shown to have significantly better OS and PFS than those with first-month RDI $<50 \%$ (HR 0.19 [CI 0.08-0.48], $\mathrm{p}=0.0004$ and HR 0.2 [CI $0.08-0.52] \mathrm{p}=0.0008$ ), and a first month-RDI $\geq 50 \%$ (HR 0.18 [CI 0.06-0.55] $\mathrm{p}=0.002$ ) and a hand-foot skin reaction (HR 0.03 [CI 0.008-0.16] p < 0.0001) were independently correlated with OS.

Therefore, Sorafenib-regorafenib sequential treatment is effective and well-tolerated in Japanese patients with unresectable hepatocellular carcinoma. A first month-RDI of $\geq 50 \%$ regorafenib has proven clinical relevance and, if confirmed in larger studies, could be a useful tool to assist second-line therapy. 
Finally, regorafenib also proved to be effective in sorafenib-tolerant patients with recurrent $\mathrm{HCC}$ after liver transplantation who develop progression in is a retrospective, multicenter, international study with a median OS of 12.9 months after starting regorafenib and 38.4 months after initiation of sorafenib (18.5-58.4 $95 \% \mathrm{CI}$ ) for sorafenib-regorafenib sequential treatment.

The AEs reported in the study were not only similar to those reported in the registration study but also comparable to those reported in similar patients receiving previous sorafenib treatment. ${ }^{69}$

\section{Prognostic Markers Associated with Response to Regorafenib}

Following the development of new effective systemic therapies for HCC, the current challenge is the correct selection of patients to orient the appropriate choice of treatment.

The identification of relevant predictive markers for clinical outcomes associated with regorafenib treatment is critical. However, to date, no established biomarkers have been identified.

In the absence of clinical/biological predictors to identify potentially responsive patients, a retrospective biomarker analysis was performed on patients enrolled in the RESORCE trial to identify biomarkers potentially predictive of benefit for regorafenib in HCC. ${ }^{70}$

Plasma and tumor samples from RESORCE study participants were evaluated in 567 patients (374 regorafenib arm and 193 placebo arm) to identify genetic, microRNA (miRNA), and protein biomarkers associated with response to regorafenib.

Remarkably, nine miRNAs (MIR30A, MIR122, MIR125B, MIR200A, MIR374B, MIR15B, MIR107, MIR320, and MIR645) plasma levels were identified as significantly related to overall survival time with regorafenib. Also, five proteins were identified as predictors of the benefit of regorafenib treatment for OS (angiopoietin 1 [ANG-1], cystatin B, transforming growth factor-beta 1 latency-associated peptide [LAP TGF-b1], oxidized lowdensity lipoprotein receptor 1 [LOX-1], C-C motif chemokine ligand 3 [MIP-1a] with decreased levels associated with the benefit of regorafenib treatment).

Currently, this is the only study that provides a possible biomarker-guided strategy for the identification of patients potentially responsive to regorafenib, but it still needs validation in further studies.
It has been suggested that Tie2 is a potential circulating biomarker of tumor vascular response for VEGF inhibitors assuming that Tie2 originates from the tumor blood vessels. $^{71}$

Since oncological use of anti-angiogenic VEGF inhibitors has been limited by the lack of informative biomarkers, circulating Tie 2 could be a candidate tumor vascular response biomarker for VEGF inhibitors.

Interestingly, during regorafenib treatment a dynamic modification of plasma angiogenic components has been reported: low baseline levels of angiopoietin-2 and Tie-2 appear to be related to a better prognosis and early modulation of Ang-2 levels may be predictive of response to regorafenib in patients with metastatic colorectal cancer.

Such results would justify an exploratory study to confirm this prognostic correlation in HCC patients. ${ }^{72}$

\section{Combination of Regorafenib with Other Systemic Agents}

In recent years, encouraging data that would promote the combination of antiangiogenic effects of regorafenib with ICIs to optimize and increase the response rate of the two individual therapies have been reported. ${ }^{73,74}$

Since TME, a key determinant of tumor growth and metastasis is characterized by multiple counterparts including immune and non-immune cell populations as well as non-cellular components, combination use of current TKIs with immunotherapy has been investigated to maximally exploit the therapeutic benefit. ${ }^{75,76}$

Regorafenib within the sub-micromolar range was found to induce M1 macrophage polarization and enhance $\mathrm{CD} 8+\mathrm{T}$ cells proliferation and activation of (Figure 2). Besides, in vivo studies using regorafenib at low-dose (3-5 $\mathrm{mg} / \mathrm{kg} /$ day), representing approximately $50 \%$ of the recommended single-agent dosage in the clinic showed synergistic antitumor efficacy with anti-PD-1 therapy. ${ }^{22}$

Identifying the optimal immunomodulatory-effects of targeted-agents is therefore crucial for the development of combination immunotherapy to enhance the therapeutic index and to tailor the use of targeted drugs to their biologically active and clinically significant dosage. ${ }^{21}$

The limitations of monotherapy approaches in HCC have led to the development of combination strategies using anti-VEGFR and anti-PD1/PD-L1 to address mechanisms of treatment resistance and achieve synergy by increasing tumor infiltration of effector T cells. ${ }^{22}$ 
One of the key elements of the efficacy of combination therapies with anti-VEGF, such as regorafenib plus immunotherapy, is to maintain a functional (normalized) vasculature and reduce hypoxia. Of note, recent studies have also shown that antitumor immune responses and vascular normalization can be reciprocally regulated by $\mathrm{CD} 4+$ $\mathrm{T}$ effector cells in other cancers. ${ }^{40,77-81}$

In HCC, dual VEGFR-2/PD1 blockade using antibodies has recently been shown to normalize tumor vasculature and induce antitumor immunity in a preclinical animal model with underlying liver damage. ${ }^{82}$

The use of combination therapy with anti-VEGF (bevacizumab) and anti-PD-L1 (atezolizumab) monoclonal antibodies has been shown to significantly increase survival compared with sorafenib in the randomized phase III IMBRAVE150 study. ${ }^{14}$

Therefore, combination approaches using multitarget TKI, such as regorafenib, that are not restricted to VEGF alone, could achieve higher efficacy outcomes and are currently under investigation.

In a preclinical study, it has been reported that in a combination treatment with anti-PD-1 antibody, regorafenib can significantly enhance PD1 blockade effects in a dose-dependent manner in HCC models. ${ }^{40}$

The benefit was due to the activity of the two agents on both normalizations of the HCC vasculature and stimulation of anti-tumor immunity. The combination treatment inhibited STAT3 activity and increased the expression of the chemokine CXCL10, which increased both tumor penetration and survival of activated CD8 T cells.

This concept is clinically relevant for the future design of combination treatment strategies in HCC patients.

The potential synergistic antitumor efficacy of regorafenib with anti-PD1 therapy has been also shown in a study of an orthotopic HCC model demonstrating that regorafenib may modulate macrophage polarization, increase $T$ cell activation, and thereby enhance the efficacy of anti-PD1 therapy for HCC. ${ }^{83}$

In a recent open-label, dose-escalation Ib study another TKIs/ICI combination treatment based on regorafenib plus pembrolizumab, an anti-PD-1 monoclonal antibody, was tested in patients with advanced HCC who received no previous systemic treatment (NCT03347292). ${ }^{84}$

In the first cohort, patients underwent regorafenib $120 \mathrm{mg} /$ day PO for three weeks on/1 week off with pembrolizumab $200 \mathrm{mg}$ IV q 3 weeks. Thereafter, the regorafenib dose could be increased $(160 \mathrm{mg}$ ) or lowered $(80 \mathrm{mg}$ ) according to the modified toxicity probability interval design, while the dosage of pembrolizumab was steady. The primary endpoints were tolerability and safety. Secondary aims were to define the maximum tolerated dose (MTD) and recommended phase 2 dose and to assess anti-tumor efficacy. Twenty-nine patients received regorafenib $120 \mathrm{mg}$ dosage. The median age was 65 years (range $32-81$ ), $41 \%$ and $55 \%$ of patients had BCLC stage B and C respectively, while $100 \%$ were Child-Pugh A class; ECOG status $1 / 0$ was $28 \% / 72 \%$. Dose-limiting toxicities were reported in $4 / 18$ evaluable patients: grade 3 raised AST/ALT with grade 2 elevated bilirubin $(n=2)$; grade 3 rash $(n=2)$. The MTD of regorafenib in the combined treatment was $120 \mathrm{mg}$.

There were no grade 5 TEAEs. Dose modifications (interruption and/or dose reduction) of regorafenib/pembrolizumab for drug-related TEAEs were reported in 59\%/ $31 \%$ of patients.

Of 23 assessable patients, 7 (30\%) exhibited a partial response and $14(61 \%)$ showed stable disease (according to RECIST v1.1). One additional patient had a partial response (according to mRECIST). Thus, the combined treatment with regorafenib plus pembrolizumab as firstline therapy of advanced HCC showed encouraging signs of anti-tumor activity and safety profile.

Enrolment has been continued and is ongoing at regorafenib $120 \mathrm{mg}$ dose.

Nivolumab is a human immunoglobulin G4 (IgG4) monoclonal antibody to the programmed death (PD)-1 receptor, which blocks the interaction with PD-ligand (PD-L)1/PD-L2 thus resuming T-cell-mediated antitumor effects, which has been approved in 2017 for the second-line treatment of HCC patients who have been previously treated with sorafenib. ${ }^{18}$

A phase I/IIa trial (NCT04170556) is ongoing and is aimed to evaluate the effects of nivolumab and regorafenib but considering the potential impact of the interaction of drugs and enhanced severity and/or frequency of AEs. ${ }^{85}$

Thus, regorafenib will be administered as monotherapy during the first 2 cycles (each cycle is 3 weeks on plus 1 week off) of treatment to enhance $T$ cell trafficking and infiltration into the tumor bed to increase the benefits of anti-PD-PD-L1.

Tislelizumab, is a humanized monoclonal antibody directed against PD-1, currently tested for hematological cancers and advanced solid tumors. ${ }^{86}$

An ongoing phase 2 study (NCT04183088) will investigate the efficacy and safety of the combined tislelizumab with regorafenib as first-line treatment for advanced HCC. ${ }^{87}$

This trial consists of 2 parts. Part 1 consists of a singlearm study and eligible patients will be assigned 
tislelizumab $200 \mathrm{mg}$ intravenously on day 1 every 3 weeks plus regorafenib $(80 \mathrm{mg} / \mathrm{d})$. Part 2 is a randomized study. Subjects will be 1:1 randomized to two treatment arms: (1) tislelizumab and regorafenib combined treatment as used in part 1, versus (2) regorafenib and placebo. For patients in group 2, when imaging assessment shows SD or PD, according to RECIST v1.1 criteria, the therapeutic strategy will be shifted to tislelizumab + regorafenib combination schedule.

Lastly, a multicenter, open-labeled prospective phase Ib trial (NCT03475953) investigating three dosage levels of Regorafenib combined with Avelumab, a human IgG1 monoclonal antibody that targets PD-L1, in both advanced and metastatic solid tumors (including HCC), is currently being recruiting. ${ }^{88}$

Ongoing clinical trials based on combined regorafenib/ ICI agents are reported in Table 3.

In addition to immunotherapy, other combination treatments of regorafenib with agents acting on parallel and complementary pathogenic pathways have also been reported in preclinical cancer models. ${ }^{22}$

Annexin A3 (ANXA3) is well known to have a key role in enhancing tumor aggressiveness, preventing apoptosis, and promoting prosurvival autophagy in sorafenibresistant HCC cells.

Tong et al demonstrated in in-vivo models of sorafenib unresponsive HCC that co-administration of regorafenib and an anti-ANXA-3 monoclonal antibody can potentiate apoptotic induction by abrogating autophagy. ${ }^{89}$ Likewise, navitoclax, a specific inhibitor of the anti-apoptotic proteins Bcl-2 and Bcl-xL, enhanced the regorafenib sensitivity of Hep3B and HepG2 cells, as evidenced by enhanced apoptotic features. ${ }^{90}$

The potential benefit of regorafenib has also been tested in combination treatment with TACE.

Regorafenib-loaded Poly(lactide-co-glycolide) (PLGA) microspheres for improvement of transarterial chemoembolization (TACE) therapeutic effects, which can sustainably deliver regorafenib to limit proangiogenic responses in liver tumors after TACE, has been recently developed. The fabricated regorafenib microspheres provided sustained drug release for more than $30 \mathrm{~d}$ in vitro and in vivo after TACE. The study demonstrated that the new regorafenib microspheres, as local drug delivery combined with TACE, may enhance the therapeutic potency of TACE for the treatment of HCC and has promising clinical implications in the future. ${ }^{91}$

\section{Discussion}

Recent studies have begun to decode the complexity of the $\mathrm{HCC}$ immune microenvironment, such as the function and subsets of different immune cells in the liver, including $\mathrm{T}$ and $\mathrm{B}$ cells, macrophages, neutrophils, NK cells, dendritic cells, myeloid-derived suppressor cells, cancerassociated fibroblasts, and the active interplay between immune cells and the cancer ecosystem in promoting angiogenesis. $^{92}$

This evidence constitutes a strong rationale supporting a therapeutic strategy that simultaneously targets the main pathogenic pathways that sustain tumor proliferation, spread, and neoangiogenesis as well as the immune mechanisms that allow tumor cells to evade immune suppression. $^{41}$

This combined approach is highly likely to lead to an enhancement of anti-tumor therapies with maximized response rates and the possibility of achieving not only disease stabilization but also tumor mass shrinkage with a higher objective response rate.

The combined use of atezolizumab with bevacizumab in first-line unresectable HCC has newly demonstrated a superior benefit over sorafenib in a recently published phase 3 trial, thus confirming that by targeting simultaneously the pathogenic pathways that support tumor growth, spread and neoangiogenesis, on the one hand, and immunosuppression and tumor-induced immune evasion on the other, the efficacy of anti-tumor treatments can be significantly improved. ${ }^{14}$

It would also be of potential interest to test whether a treatment strategy including another ICI (anti-CTLA-4) or a broad-spectrum multikinase inhibitor added to a PD-1 or PD-L1 inhibitors, could provide additional benefits. This strategy has been successfully studied in more detail in other malignant diseases such as renal cell carcinoma. $^{93-96}$

Specifically, focused studies are indispensable as feasibility and comparison of these studies with HCC patients is not practicable due to diversity in tumor biology and underlying liver disease characterizing $\mathrm{HCC}$ patients.

Another clinically relevant question will be to assess the suitability of such therapies for patients with ChildPugh class B (especially B7), which is currently still limited because these patients have been ruled out or only accounted for less than $10 \%$ of patients in studies.

However, these therapies are utilized in clinical practice with not as strict inclusion criteria as the respective phase 3 
Table 3 Ongoing Clinical Trials with Regorafenib-Based Combination Treatments (www.clinicaltrials.gov)

\begin{tabular}{|c|c|c|c|c|c|}
\hline $\begin{array}{l}\text { Clinical } \\
\text { Trials } \\
\text { Identifier }\end{array}$ & Official Title & Phase & Therapy Line & Intervention/Treatment & Status \\
\hline NCT04I83088 & $\begin{array}{l}\text { Regorafenib Plus Tislelizumab as } \\
\text { First-line Systemic Therapy for } \\
\text { Patients With Advanced } \\
\text { Hepatocellular Carcinoma }\end{array}$ & II & First & $\begin{array}{l}\text { - } \text { Tislelizumab+regorafenib for part I. } \\
\text { - Tislelizumab+regorafenib for group } \\
\text { I of part } 2 \text {. } \\
\text { - Placebo+regorafenib for group } 2 \text { of } \\
\text { part } 2 \text {. }\end{array}$ & $\begin{array}{l}\text { Not yet } \\
\text { recruiting }\end{array}$ \\
\hline NCT04I70556 & $\begin{array}{l}\text { The GOING Study: Regorafenib } \\
\text { Followed by Nivolumab in Patients } \\
\text { With Hepatocellular Carcinoma } \\
\text { Progressing Under Sorafenib }\end{array}$ & $\mathrm{l} / \mathrm{lla}$ & Second ${ }^{\wedge}$ & $\begin{array}{l}\text { - Regorafenib } 160 \mathrm{mg} / \text { day } 3 \text { weeks on } \\
\text { and I week off. } \\
\text { - Nivolumab at the dose of } 1.5 \mathrm{mg} / \\
\mathrm{kg}, 3 \mathrm{mg} / \mathrm{kg} \text { or } 240 \mathrm{mg} / \text { infusion } \\
\text { every } 2 \text { weeks. Dose will be } \\
\text { adjusted depending on the inci- } \\
\text { dence of adverse events. }\end{array}$ & Recruiting \\
\hline NCT043I0709 & $\begin{array}{l}\text { Phase II Study of Regorafenib- } \\
\text { nivolumab Combination Therapy for } \\
\text { Chemotherapy-naïe Patients With } \\
\text { Unresectable or Metastatic } \\
\text { Hepatocellular (RENOBATE) }\end{array}$ & II & First & $\begin{array}{l}\text { - Nivolumab } 480 \mathrm{mg} \text { IV on Day I, } \\
\text { every } 4 \text { weeks. } \\
\text { - Regorafenib } 80 \mathrm{mg} \text { per oral once } \\
\text { daily for } 2 \mathrm{I} \text { consecutive days starting } \\
\text { on Day I, every } 4 \text { weeks. }\end{array}$ & Recruiting \\
\hline NCT0477785I & $\begin{array}{l}\text { Phase III, Multicenter, Randomized, } \\
\text { Open-Label Trial to Evaluate Efficacy } \\
\text { and Safety of Regorafenib in } \\
\text { Combination With Nivolumab } \\
\text { Versus TACE for First-Line } \\
\text { Treatment of Intermediate-Stage } \\
\text { HCC With Beyond Up-to-7 Criteria }\end{array}$ & III & First & $\begin{array}{l}\text { Investigational arm: regorafenib at } \\
\text { a dose of } 90 \mathrm{mg} \text { orally once per day } \\
\text { (on days I to } 2 \text { I of a } 28 \text {-day cycle), in } \\
\text { combination with nivolumab } 480 \mathrm{mg} \\
\text { using } 30 \text {-minutes intravenous infusion } \\
\text { (on day I of a } 28 \text {-day cycle, every } 4 \\
\text { weeks). } \\
\text { Control arm: Patients will be } \\
\text { treated with transarterial } \\
\text { chemoembolization (TACE) "on- } \\
\text { demand" according to the clinical } \\
\text { site's standards, with the goal of } \\
\text { controlling all known liver lesions. } \\
\text { Either conventional TACE (cTACE) or } \\
\text { drug-eluting bead transarterial } \\
\text { chemoembolization (DEB-TACE) may } \\
\text { be used (as long as it is consistently } \\
\text { applied for all patients at a given } \\
\text { clinical site). }\end{array}$ & $\begin{array}{l}\text { Not yet } \\
\text { recruiting }\end{array}$ \\
\hline NCT047I8909 & $\begin{array}{l}\text { Regorafenib Combined With } \\
\text { Sintilimab Versus Regorafenib Alone } \\
\text { as the Second-line Treatment for } \\
\text { Unresectable Hepatocellular } \\
\text { Carcinoma }\end{array}$ & II & Second & $\begin{array}{l}\text { Experimental Arm: Regorafenib: } \\
160 \mathrm{mg} \text { p.o. qd for } 3 \text { weeks of every } \\
4 \text { week cycle (ie, } 3 \text { weeks on, I } \\
\text { week off). } \\
\text { Sintilimab: } 200 \mathrm{mg} \text { i.v. q3w. } \\
\text { - Active Comparator: Regorafenib: } \\
160 \mathrm{mg} \text { p.o. qd for } 3 \text { weeks of every } 4 \\
\text { week cycle (ie, } 3 \text { weeks on, I week } \\
\text { off). }\end{array}$ & Recruiting \\
\hline
\end{tabular}

(Continued) 
Table 3 (Continued).

\begin{tabular}{|c|c|c|c|c|c|}
\hline $\begin{array}{l}\text { Clinical } \\
\text { Trials } \\
\text { Identifier }\end{array}$ & Official Title & Phase & Therapy Line & Intervention/Treatment & Status \\
\hline NCT03475953 & $\begin{array}{l}\text { A Phase I/II Study of Regorafenib } \\
\text { Plus Avelumab in Solid Tumors }\end{array}$ & $1 / I I$ & $\begin{array}{l}\geq \text { I previous line (s) of systemic } \\
\text { therapy }\end{array}$ & $\begin{array}{l}\text { - } 3 \text { dose levels of Regorafenib given } \\
\text { in combination with Avelumab fol- } \\
\text { lowed by } 7 \text { phase II trials to evalu- } \\
\text { ate the association of Regorafenib } \\
\text { at the RP2D }{ }^{\S} \text { with Avelumab in } 7 \\
\text { distinct settings (advanced or } \\
\text { metastatic tumors). }\end{array}$ & Recruiting \\
\hline NCT04696055 & $\begin{array}{l}\text { An Open-Label Study of } \\
\text { Regorafenib in Combination With } \\
\text { Pembrolizumab in Patients With } \\
\text { Advanced or Metastatic } \\
\text { Hepatocellular Carcinoma (HCC) } \\
\text { After PDI/PD-LI Immune } \\
\text { Checkpoint Inhibitors }\end{array}$ & II & $\begin{array}{l}\text { Prior IL immunotherapy with } \\
\text { a PD-I/PD-LI checkpoint } \\
\text { inhibitor administered either as } \\
\text { monotherapy or in combination } \\
\text { with other therapies }\end{array}$ & $\begin{array}{l}\text { Pembrolizumab } 400 \mathrm{mg} \text { to be admi- } \\
\text { nistered as an intravenous (IV) } \\
\text { infusion every } 6 \text { weeks (Q6W). } \\
\text { - Regorafenib will be given orally (P. } \\
\text { o.) at a starting dose of } 90 \mathrm{mg} \text { QD } \\
\text { for } 3 \text { weeks of every } 4 \text { weeks (ie, } 3 \\
\text { weeks on, I week off). If the start- } \\
\text { ing dose of } 90 \mathrm{mg} \text { daily is well tol- } \\
\text { erated the dose should be escalated } \\
\text { to } 120 \mathrm{mg} \text { starting after the first } \\
\text { 4-week cycle of regorafenib. }\end{array}$ & Recruiting \\
\hline NCT03347292 & $\begin{array}{l}\text { A Multicenter, Non-randomized, } \\
\text { Open-label Dose Escalation Phase lb } \\
\text { Study of Regorafenib in } \\
\text { Combination With Pembrolizumab } \\
\text { in Patients With Advanced } \\
\text { Hepatocellular Carcinoma (HCC) } \\
\text { With no Prior Systemic Therapy }\end{array}$ & I & First & $\begin{array}{l}\text { Dose escalation: The regorafenib } \\
\text { starting dose will be } 120 \mathrm{mg} \text { q.d. } \\
\text { (once daily) } 3 \text { weeks on/I week off } \\
\text { in combination with the recom- } \\
\text { mended dose of pembrolizumab } \\
\text { (200 mg Q3W). Pembrolizumab } \\
\text { dose will not be escalated or de- } \\
\text { escalated. } \\
\text { - Dose expansion: Dose expansion } \\
\text { cohorts will continue to be } \\
\text { expanded until the sample size of } \\
30-35 \text { patients per cohort is } \\
\text { reached. }\end{array}$ & $\begin{array}{c}\text { Active, } \\
\text { not } \\
\text { recruiting }\end{array}$ \\
\hline
\end{tabular}

Note: ^Patients progressing under first-line sorafenib.

Abbreviation: ${ }^{\S} \mathrm{RP} 2 \mathrm{D}$, recommended phase II dose.

studies. ${ }^{21,60,67}$ For instance, in the prospective observational study (REFINE) of regorafenib in HCC patients, $11 \%$ of treated patients had Child-Pugh B liver function and $28 \%$ of total patients were initiated on $80 \mathrm{mg}$ of regorafenib rather than the standard $160 \mathrm{mg}$ dose. ${ }^{21}$ These dose modifications to attenuate TKI-related AEs without affecting efficacy have been prospectively analyzed in metastatic colorectal cancer, where a dose-escalation approach to regorafenib showed favorable AEs and comparable therapeutic efficacy to the entire dose. ${ }^{97}$ Equally, sorafenib at $200 \mathrm{mg}$ proved more tolerable than the $400 \mathrm{mg}$ dose with comparable efficacy in a large retrospective study. ${ }^{98,99}$
Regorafenib, due to its broad spectrum of inhibition of tumor angiogenesis and its favorable effects on macrophage polarization and cytotoxic CD8+ lymphocyte activity, is a strong candidate for combination therapy strategies with ICIs.A recent meta-analysis based mainly on realworld studies investigating regorafenib assecond-line therapy after sorafenib failure confirms the promising favorable outcomes observed with the RESORCE trial and demonstrates that regorafenib provides both valid and safe treatment strategy in patients with intermediate/ advanced HCC who exhibit disease progression on sorafenib. ${ }^{100}$ 
In the next future, new clinical trials for $\mathrm{HCC}$ patients should be aimed at investigating the potential benefit and synergistic effects of regorafenib with ICIs. ${ }^{60}$,

A key step in the development of optimal systemic treatment strategies for HCC remains the identification of clinical-biological markers of efficacy and thus predictive biomarker's discovery is critical for the fine-tuning of regorafenib treatment. ${ }^{70}$

New combined therapeutic approaches of regorafenib with other ICIs or TKIs provide an interesting opportunity for continued research and in the near future is expected to be a breakthrough for patients with unresectable HCC. It will therefore be critical to have in-depth knowledge of the pharmacological characteristics of each drug and the most appropriate management of possible AEs to achieve maximum therapeutic benefit.

\section{Funding}

The authors received no financial support to produce this manuscript.

\section{Disclosure}

Fabio Piscaglia has received personal fees for speakers' bureaus and advisory boards and for being a consultant from Alkermes, AstraZeneca, Bayer, Bracco, Bristol Myers Squibb, Eisai, GE Healthcare, Ipsen, La Force Guerbet, Roche and Tiziana Life Sciences.

Francesco Tovoli reports personal fees from Bayer AG, Guerbet, and Ipsen, outside the submitted work; consultant for Bayer, speaker bureau honoraria from MSD, and grant from Ipsen.

The authors reported no other potential conflicts of interest for this work.

\section{References}

1. Global Cancer Observatory (GCO)@GLOBOCAN_GCO. Available from: https://gco.iarc.fr/today/home. Accessed April 20, 2021.

2. El-Serag HB. Epidemiology of viral hepatitis and hepatocellular carcinoma. Gastroenterology. 2012;142(6):1264-1273. doi:10.1053/j. gastro.2011.12.061

3. White DL, Thrift AP, Kanwal F, Davila J, El-Serag HB. Incidence of hepatocellular carcinoma in all 50 United States, from 2000 through 2012. Gastroenterology. 2017;152(4):812-820, e5. doi:10.1053/j. gastro.2016.11.020

4. Singal AG, Lampertico P, Nahon P. Epidemiology and surveillance for hepatocellular carcinoma: new trends. J Hepatol. 2020;72(2):250-261. doi:10.1016/j.jhep.2019.08.025

5. Siegel AB, Zhu AX. Metabolic syndrome and hepatocellular carcinoma: two growing epidemics with a potential link. Cancer. 2009;115:5651-5661. doi:10.1002/cncr.24687
6. Baffy G, Brunt EM, Caldwell SH. Hepatocellular carcinoma in non-alcoholic fatty liver disease: an emerging menace. $J$ Hepatol. 2012;56:1384-1391. doi:10.1016/j.jhep.2011.10.027

7. Dyson J, Jaques B, Chattopadyhay D, et al. Hepatocellular cancer: the impact of obesity, type 2 diabetes and a multidisciplinary team. J Hepatol. 2014;60:110-117. doi:10.1016/j.jhep.2013.08.011

8. Singal AK, Singh A, Jaganmohan S, et al. Antiviral therapy reduces risk of hepatocellular carcinoma in patients with hepatitis C virus-related cirrhosis. Clin Gastroenterol Hepatol. 2010;8:192-199. doi:10.1016/j.cgh.2009.10.026

9. Morgan TR, Ghany MG, Kim HY, et al. Outcome of sustained virological responders with histologically advanced chronic hepatitis C. Hepatology. 2010;52:833-844. doi:10.1002/hep.23744

10. Santi V, Buccione D, Di Micoli A, et al. The changing scenario of hepatocellular carcinoma over the last two decades in Italy. J Hepatol. 2012;56(2):397-405. doi:10.1016/j.jhep.2011.05.026

11. Simmons B, Saleem J, Heath K, Cooke GS, Hill A. Long-term treatment outcomes of patients infected with hepatitis $\mathrm{C}$ virus: a systematic review and meta-analysis of the survival benefit of achieving a sustained virological response. Clin Infect Dis. 2015;61:730-740. doi:10.1093/cid/civ396

12. Llovet JM, Ricci S, Mazzaferro V, et al. Sorafenib in advanced hepatocellular carcinoma. $N$ Engl J Med. 2008;359:378-390. doi:10.1056/NEJMoa0708857

13. Kudo M, Finn RS, Qin S, et al. Lenvatinib versus sorafenib in first-line treatment of patients with unresectable hepatocellular carcinoma: a randomised phase 3 non-inferiority trial. Lancet. 2018;391:1163-1173. doi:10.1016/S0140-6736(18)30207-1

14. Finn RS, Qin S, Ikeda M, et al. Atezolizumab plus Bevacizumab in Unresectable Hepatocellular Carcinoma. $N$ Engl $J$ Med. 2020;382(20):1894-1905. doi:10.1056/NEJMoa1915745

15. Bruix J, Qin S, Merle P, et al. Regorafenib for patients with hepatocellular carcinoma who progressed on sorafenib treatment (RESORCE): a randomised, double-blind, placebo-controlled, phase 3 trial. Lancet. 2017;389:56-66. doi:10.1016/S0140-6736(16)32453-9

16. Abou-Alfa GK, Meyer T, Cheng AL, et al. Cabozantinib in patients with advanced and progressing hepatocellular carcinoma. $N$ Engl J Med. 2018;379:54-63. doi:10.1056/NEJMoa1717002

17. Zhu AX, Kang YK, Yen CJ, et al. Ramucirumab after sorafenib in patients with advanced hepatocellular carcinoma and increased alpha-fetoprotein concentrations (REACH-2): a randomised, double-blind, placebo-controlled, phase 3 trial. Lancet Oncol. 2019;20:282-296. doi:10.1016/S1470-2045(18)30937-9

18. El-Khoueiry AB, Sangro B, Yau T, et al. Nivolumab in patients with advanced hepatocellular carcinoma (CheckMate 040): an open-label, noncomparative, Phase 1/2 dose escalation and expansion trial. Lancet. 2017;389:2492-2502. doi:10.1016/S0140-6736(17)31046-2

19. Zhu AX, Finn RS, Edeline J, et al. Pembrolizumab in patients with advanced hepatocellular carcinoma previously treated with sorafenib (KEYNOTE-224): a non-randomised, open-label phase 2 trial. Lancet Oncol. 2018;19(7):940-952. doi:10.1016/S14702045(18)30351-6

20. Yau T, Kang Y, Kim T, et al. Efficacy and safety of nivolumab plus ipilimumab in patients with advanced hepatocellular carcinoma previously treated with sorafenib: the CheckMate 040 Randomized Clinical Trial. JAMA Oncol. 2020;6(11):e204564. doi:10.1001/jamaoncol.2020.4564

21. Lim HY, Merle P, Finn RS, et al. Regorafenib in patients with unresectable hepatocellular carcinoma (uHCC) in routine clinical practice: interim analysis of the prospective, observational REFINE trial. J Clin Oncol. 2020;38(suppl 4):542. doi:10.1200/ JCO.2020.38.4_suppl.542

22. Cheng AL, Hsu C, Chan SL, Choo SP, Kudo M. Challenges of combination therapy with immune checkpoint inhibitors for hepatocellular carcinoma. J Hepatol. 2020;72:307-319. doi:10.1016/j. jhep.2019.09.025 
23. Fondevila F, Méndez-Blanco C, Fernández-Palanca P, GonzálezGallego J, Mauriz JL. Anti-tumoral activity of single and combined regorafenib treatments in preclinical models of liver and gastrointestinal cancers. Exp Mol Med. 2019;51:1-15. doi:10.1038/s12276-019-0308-1

24. Wilhelm SM, Dumas J, Adnane L, et al. Regorafenib (BAY 73-4506): a new oral multikinase inhibitor of angiogenic, stromal and oncogenic receptor tyrosine kinases with potent preclinical antitumor activity. Int J Cancer. 2011;129:245-255. doi:10.1002/ijc.25864

25. Wai Ling Khoo TS, Rehman A, Olynyk JK. Tyrosine kinase inhibitors in the treatment of hepatocellular carcinoma. In: Tirnitz-Parker JEE, editor. Hepatocellular Carcinoma [Internet]. Brisbane (AU): Codon Publications; October 24, 2019. Chapter 7.

26. Eso Y, Marusawa H. Novel approaches for molecular targeted therapy against hepatocellular carcinoma. Hepatol Res. 2018;48 (8):597-607. doi:10.1111/hepr.13181

27. Kudo M. Targeted and immune therapies for hepatocellular carcinoma: predictions for 2019 and beyond. World J Gastroenterol. 2019;25:789-807. doi:10.3748/wjg.v25.i7.789

28. Mody K, Abou-Alfa GK. Systemic therapy for advanced hepatocellular carcinoma in an evolving landscape. Curr Treat Options Oncol. 2019;20:3. doi:10.1007/s11864-019-0601-1

29. Abou-Elkacem L, Arns S, Brix G, et al. Regorafenib inhibits growth, angiogenesis, and metastasis in a highly aggressive, orthotopic colon cancer model. Mol Cancer Ther. 2013;12 (7):1322-1331. doi:10.1158/1535-7163.MCT-12-1162

30. Schmieder R, Hoffmann J, Becker M, et al. Regorafenib (BAY 73-4506): antitumor and antimetastatic activities in preclinical models of colorectal cancer. Int J Cancer. 2014;135:1487-1496. doi:10.1002/ijc. 28669

31. Zopf D, Fichtner I, Bhargava A, et al. Pharmacologic activity and pharmacokinetics of metabolites of regorafenib in preclinical models. Cancer Med. 2016;5:3176. doi:10.1002/cam4.883

32. Arai H, Battaglin F, Wang J, et al. Molecular insight of regorafenib treatment for colorectal cancer. Cancer Treat Rev. 2019;81:101912. doi:10.1016/j.ctrv.2019.101912

33. Hu W, Li X, Zhang C, Yang Y, Jiang J, Wu C. Tumor-associated macrophages in cancers. Clin Transl Oncol. 2016;18:251-258. doi:10.1007/s12094-015-1373-0

34. Kang FB, Wang L, Li D, Zhang YG, Sun DX. Hepatocellular carcinomas promote tumor-associated macrophage M2-polarization via increased B7-H3 expression. Oncol Rep. 2015;33:274-282. doi:10.3892/or.2014.3587

35. Zhou D, Luan J, Huang C, Li J. Tumor-associated macrophages in hepatocellular carcinoma: friend or foe? Gut Liver. 2020. doi:10.5009/gn120223

36. Cannarile MA, Weisser M, Jacob W, Jegg AM, Ries $\mathrm{CH}$, Ruttinger D. Colony-stimulating factor 1 receptor (CSF1R) inhibitors in cancer therapy. J Immunother Cancer. 2017;5:53. doi:10.1186/s40425-017-0257-y

37. Duan S, Guo W, Xu Z, et al. Natural killer group 2D receptor and its ligands in cancer immune escape. Mol Cancer. 2019;18:29. doi:10.1186/s12943-019-0956-8

38. Tai WT, Chu PY, Shiau CW, et al. STAT3 mediates regorafenib-induced apoptosis in hepatocellular carcinoma. Clin Cancer Res. 2014;20(22):5768-5776. doi:10.1158/1078-0432.CCR14-0725

39. Uschner FE, Schueller F, Nikolova I, et al. The multikinase inhibitor regorafenib decreases angiogenesis and improves portal hypertension. Oncotarget. 2018;9(90):36220-36237. doi:10.186 32/oncotarget. 26333
40. Shigeta K, Matsui A, Kikuchi H, et al. Regorafenib combined with PD1 blockade increases CD8 T-cell infiltration by inducing CXCL10 expression in hepatocellular carcinoma. J Immunother Cancer. 2020;8:e001435. doi:10.1136/jitc-2020-001435

41. Raybould AL, Sanoff H. Combination antiangiogenic and immunotherapy for advanced hepatocellular carcinoma: evidence to date. J Hepatocell Carcinoma. 2020;7:133-142. doi:10.2147/JHC.S224938

42. da Fonseca LG, Reig M, Bruix J. Tyrosine kinase inhibitors and hepatocellular carcinoma. Clin Liver Dis. 2020;24(4):719-737. doi:10.1016/j.cld.2020.07.012

43. Strumberg D, Scheulen M, Schultheis B, et al. Regorafenib (BAY 73-4506) in advanced colorectal cancer: a Phase I study. $\mathrm{Br}$ $J$ Cancer. 2012;106(11):1722-1727. doi:10.1038/bjc.2012.153

44. van Leeuwen RWF, van Gelder T, Mathijessen RHJ, Jansman FGA. Drug-drug interactions with tyrosine-kinase inhibitors: a clinical perspective. Lancet Oncol. 2014;15:e315-e326. doi:10.1016/S1470-2045(13)70579-5

45. Wilhelm SM, Carter C, Tang L, et al. BAY 43-9006 exhibits broad spectrum oral antitumor activity and targets the RAF/ MEK/ERK pathway and receptor tyrosine kinases involved in tumor progression and angiogenesis. Cancer Res. 2004;64:7099-7109. doi:10.1158/0008-5472.CAN-04-1443

46. Bruix J, Tak WY, Gasbarrini A, et al. Regorafenib as second-line therapy for intermediate or advanced hepatocellular carcinoma: multicentre, open-label, phase II safety study. Eur J Cancer. 2013;49:3412-3419. doi:10.1016/j.ejca.2013.05.028

47. Bruix J, Merle P, Granito A, et al. Updated overall survival (OS) analysis from the international, Phase3, randomized, placebo-controlled RESORCE trial of regorafenib for patients with hepatocellular carcinoma (HCC) who progressed on sorafenib treatment. Ann Oncol. 2017;28:iii140. doi:10.1093/annonc/ mdx262.008

48. Bruix J, Merle P, Granito A, et al. Comparison of modified (m) RECISTand RECIST 1.1 assessments in the phase 3 RESORCE trial comparing regorafenib and placebo in patients with hepatocellular carcinoma who progressed during sorafenib treatment. $J$ Hepatol. 2017;66:S451-S452. doi:10.1016/S0168-8278(17) 31281-3

49. Tovoli F, Renzulli M, Granito A, Golfieri R, Bolondi L. Radiologic criteria of response to systemic treatments for hepatocellular carcinoma. Hepat Oncol. 2017;4(4):129-137. doi:10.2217/hep-2017-0018

50. Bruix J, Merle P, Granito A, et al. Survival by pattern of tumor progression during prior sorafenib (SOR) treatment in patients with hepatocellular carcinoma (HCC) in the phase III RESORCE trial comparing second-line treatment with regorafenib (REG) or placebo. J Clin Oncol. 2017;35(4_suppl):229. doi:10.1200/ JCO.2017.35.4_suppl.229

51. Bruix J, Merle P, Granito A, et al. Hand-foot skin reaction (HFSR) and overall survival (OS) in the phase 3 RESORCE trial of regorafenib for treatment of hepatocellular carcinoma (HCC) progressing on sorafenib. J Clin Oncol. 2018;36 (4_suppl):412. doi:10.1200/JCO.2018.36.4_suppl.412

52. Granito A, Marinelli S, Negrini G, Menetti S, Benevento F, Bolondi L. Prognostic significance of adverse events in patients with hepatocellular carcinoma treated with sorafenib. Therap Adv Gastroenterol. 2016;9:240-249. doi:10.1177/1756283X15618129

53. Finn RS, Merle P, Granito A, et al. Outcomes of sequential treatment with sorafenib followed by regorafenib for HCC: additional analyses from the phase III RESORCE trial. $J$ Hepatol. 2018;69:353-358. doi:10.1016/j.jhep.2018.04.010 
54. Observational study to evaluate, under real-world practice conditions, the safety and effectiveness of regorafenib in patients diagnosed with unresectable hepatocellular carcinoma (uHCC). Available from: https://clinicaltrials.gov/ct2/show/ NCT03289273. Accessed April 20, 2021.

55. Merle P, Lim HY, Finn RS, et al. Sequential treatment with sorafenib followed by regorafenib in patients with unresectable hepatocellular carcinoma (HCC): interim analysis of the observational REFINE study. $J$ Clin Oncol. 2020;38(15_suppl):e16680-e16680. doi:10.1200/JCO.2020. 38.15_suppl.e16680

56. Yoo $\bar{C}$, Park J-W, Kim YJ, et al. Multicenter retrospective analysis of the safety and efficacy of regorafenib after progression on sorafenib in Korean patients with hepatocellular carcinoma. Invest New Drugs. 2019;37:567-572. doi:10.1007/ s10637-018-0707-5

57. Yoo C, Byeon S, Bang Y, et al. Regorafenib in previously treated advanced hepatocellular carcinoma: impact of prior immunotherapy and adverse events. Liver Int. 2020;40:2263-2271. doi:10.1111/liv.14496

58. Fung AS, Tam VC, Meyers DE, et al. Second-line treatment of hepatocellular carcinoma after sorafenib: characterizing treatments used over the past 10 years and real-world eligibility for cabozantinib, regorafenib, and ramucirumab. Cancer Med. 2020;9:4640-4647. doi:10.1002/cam4.3116

59. Kuzuya T, Uchikawa S, Kawaoka T, et al. Clinical outcomes of sorafenib treatment failure for advanced hepatocellular carcinoma and candidates for regorafenib treatment in real-world practice. Hepatol Res. 2018;48:814-820. doi:10.1111/hepr.13180

60. Granito A, Bolondi L. Non-transplant therapies for patients with hepatocellular carcinoma and Child-Pugh-Turcotte class B cirrhosis. Lancet Oncol. 2017;18:e101-e112. doi:10.1016/ S1470-2045(16)30569-1

61. Ogasawara S, Chiba T, Ooka Y, et al. Characteristics of patients with sorafenib-treated advanced hepatocellular carcinoma eligible for second-line treatment. Invest New Drugs. 2018;36:332-339. doi:10.1007/s10637-017-0507-3

62. Terashima T, Yamashita T, Sunagozaka H, et al. Analysis of the liver functional reserve of patients with advanced hepatocellular carcinoma undergoing sorafenib treatment: prospects for regorafenib therapy. Hepatol Res. 2018;48:956-966. doi:10.1111/ hepr. 13196

63. Johnson PJ, Berhane S, Kagebayashi C, et al. Assessment of liver function in patients with hepatocellular carcinoma: a new evidence-based approach-the ALBI grade. $J$ Clin Oncol. 2015;33:550-558. doi:10.1200/JCO.2014.57.9151

64. Yukimoto A, Hirooka M, Hiraoka A, et al. Using ALBI score at the start of sorafenib treatment to predict regorafenib treatment candidates in patients with hepatocellular carcinoma. Jpn J Clin Oncol. 2019;49:42-47. doi:10.1093/jjco/hyy153

65. Takada H, Kurosaki M, Tsuchiya K, et al. Baseline and early predictors of good patient candidates for second-line after sorafenib treatment in unresectable hepatocellular carcinoma. Cancers. 2019;11:1256. doi:10.3390/cancers 11091256

66. Moriguchi M, Aramaki T, Sato R, et al. Intrahepatic tumor burden as a novel factor influencing the introduction of second-line chemotherapy for hepatocellular carcinoma. Anticancer Res. 2020;40:3953-3960. doi:10.21873/anticanres.14387

67. Kim HD, Bang Y, Lee MA, et al. Regorafenib in patients with advanced Child-Pugh B hepatocellular carcinoma: a multicentre retrospective study. Liver Int. 2020;40:2544-2552. doi:10.1111/ liv. 14573
68. Wang W, Tsuchiya K, Kurosaki M, et al. Sorafenib-regorafenib sequential therapy in Japanese patients with unresectable hepatocellular carcinoma-relative dose intensity and post-regorafenib therapies in real world practice. Cancers (Basel). 2019;11:1517. doi:10.3390/cancers11101517

69. Iavarone M, Invernizzi F, Czauderna C, et al. Preliminary experience on safety of regorafenib after sorafenib failure in recurrent hepatocellular carcinoma after liver transplantation. Am J Transplant. 2019;19:3176-3184. doi:10.1111/ajt.15551

70. Teufel M, Seidel H, Köchert K, et al. Biomarkers associated with response to regorafenib in patients with hepatocellular carcinoma. Gastroenterology. 2019;156:1731-1741. doi:10.1053/j.gastro.20 19.01.261

71. Jayson GC, Zhou C, Backen A, et al. Plasma Tie2 is a tumor vascular response biomarker for VEGF inhibitors in metastatic colorectal cancer. Nat Commun. 2018;9:4672. doi:10.1038/ s41467-018-07174-1

72. Antoniotti C, Marmorino F, Pennati M, et al. Circulating angiogenesis-related markers as predictors of benefit from regorafenib in metastatic colorectal cancer (mCRC) patients (pts). $J$ Clin Oncol. 2018;36(4_suppl):675. doi:10.1200/JCO.2018. 36.4_suppl.675

73. Okusaka T, Ikeda M. Immunotherapy for hepatocellular carcinoma: current status and future perspectives. ESMO Open. 2018;3(Suppl 1):e000455. doi:10.1136/esmoopen-2018-000 455

74. Liu JY, Chiang T, Liu CH, et al. Delivery of siRNA using CXCR4-targeted nanoparticles modulates tumor microenvironment and achieves a potent antitumor response in liver cancer. Mol Ther. 2015;23:1772-1782. doi:10.1038/mt.2015.147

75. Faivre S, Rimassa L, Finn RS. Molecular therapies for HCC: looking outside the box. J Hepatol. 2020;72:342-352. doi:10. 1016/j.jhep.2019.09.010

76. Tsai AK, Khan AY, Worgo CE, Wang LL, Liang Y, Davila E. A multikinase and DNA-PK inhibitor combination immunomodulates melanomas, suppresses tumor progression, and enhances immunotherapies. Cancer Immunol Res. 2017;5:790-803. doi:10.1158/2326-6066.CIR-17-0009

77. Fukumura D, Kloepper J, Amoozgar Z, et al. Enhancing cancer immunotherapy using antiangiogenics: opportunities and challenges. Nat Rev Clin Oncol. 2018;15:325-340. doi:10.1038/ nrclinonc.2018.29

78. Hamzah J, Jugold M, Kiessling F, et al. Vascular normalization in Rgs5-deficient tumours promotes immune destruction. Nature. 2008;453:410-414. doi:10.1038/nature06868

79. Jain RK. Antiangiogenesis strategies revisited: from starving tumors to alleviating hypoxia. Cancer Cell. 2014;26:605-622. doi:10.1016/j.ccell.2014.10.006

80. Huang Y, Yuan J, Righi E, et al. Vascular normalizing doses of antiangiogenic treatment reprogram the immunosuppressive tumor microenvironment and enhance immunotherapy. Proc Natl Acad Sci U S A. 2012;109:17561-17566. doi:10.1073/ pnas. 1215397109

81. Tian L, Goldstein A, Wang H, et al. Mutual regulation of tumor vessel normalization and immunostimulatory reprogramming. Nature. 2017;544:250-254. doi:10.1038/nature21724

82. Shigeta K, Datta $M$, Hato $T$, et al. Dual programmed death receptor-1 and vascular endothelial growth factor receptor-2 blockade promotes vascular normalization and enhances antitumor immune responses in hepatocellular carcinoma. Hepatology. 2020;71:1247-1261. doi:10.1002/hep.30889 
83. Chen CW, Ou DL, Hsu CL, Lin L, Cheng AL, Hsu C. Regorafenib may enhance efficacy of anti-program cell death-1 (PD-1) therapy in hepatocellular carcinoma (HCC) through modulation of macrophage polarization. International Liver Congress. J Hepatol. 2019;70(suppl):e605-e606. doi:10.1016/S0618-8278(19)31207-1

84. Waldschmidt D, El-Khoueir AB, Kim RD, et al. Phase 1b study of regorafenib (REG) plus pembrolizumab (PEMBRO) for first-line treatment of advanced hepatocellular carcinoma (HCC). Oncol Res Treat. 2020;43(SUPPL 4):123.

85. Regorafenib Followed by Nivolumab in Patients With Hepatocellular Carcinoma (GOING). Available from: https://clin icaltrials.gov/ct2/show/NCT04170556. Accessed April 20, 2021.

86. Lee A, Keam SJ. Tislelizumab: first approval. Drugs. 2020;80:617-624. doi:10.1007/s40265-020-01286-z

87. Regorafenib plus tislelizumab as first-line systemic therapy for patients with advanced hepatocellular carcinoma. Available from: https://www.clinicaltrials.gov/ct2/show/NCT04183088?id= $\mathrm{NCT} 04476329+\mathrm{OR}+\mathrm{NCT} 04183088+\mathrm{OR}+\mathrm{NCT} 04327700+\mathrm{OR}$ $+\mathrm{NCT} 04170556+\mathrm{OR}+\mathrm{NCT} 02162914+\mathrm{OR}+\mathrm{NCT} 04310709+\mathrm{OR}$ $+\mathrm{NCT} 03644511+\mathrm{OR}+\mathrm{NCT} 03347292+\mathrm{OR}+\mathrm{NCT} 01466504+\mathrm{OR}$ $+\mathrm{NCT} 03956940+\mathrm{OR}+\mathrm{NCT} 03899428 \&$ draw $=2 \&$ rank $=4 \&$ load $=$ cart. Accessed April 20, 2021.

88. A Phase I/II Study of regorafenib plus avelumab in solid tumors (REGOMUNE). Available from: https://clinicaltrials.gov/ct2/ show/NCT03475953. Accessed April 20, 2021.

89. Tong M, Che N, Zhou L, et al. Efficacy of annexin A3 blockade in sensitizing hepatocellular carcinoma to sorafenib and regorafenib. $J$ Hepatol. 2018;69:826-839. doi:10.1016/j. jhep.2018.05.034

90. Tutusaus A, Stefanovic M, Boix L, et al. Antiapoptotic BCL-2 proteins determine sorafenib/regorafenib resistance and BH3-mimetic efficacy in hepatocellular carcinoma. Oncotarget. 2018;9:16701-16717. doi:10.18632/oncotarget.24673

91. Li X, He G, Su F, et al. Regorafenib-loaded poly (lactide-coglycolide) microspheres designed to improve transarterial chemoembolization therapy for hepatocellular carcinoma. Asian J Pharm Sci. 2020;15(6):739-751. doi:10.1016/j.ajps.2020.01. 001

92. Feng M, Pan Y, Kong R, Shu S. Therapy of primary liver cancer. Innovation ( $N$ Y). 2020;1:100032. doi:10.1016/j.xinn.2020.10 0032
93. McKay RR, Xie W, McGregor BA, et al. Optimized management of nivolumab (Nivo) and ipilimumab (Ipi) in advanced renal cell carcinoma (RCC): a response-based phase II study (OMNIVORE). J Clin Oncol. 2020;38(Suppl_15):5005. doi:10.1200/JCO.2020.38.15_suppl.5005

94. Atkins MB, Jegede O, Haas NB, et al. Phase II study of nivolumab and salvage nivolumab + ipilimumab in treatment-naïve patients with advanced renal cell carcinoma (RCC) (HCRN GU16-260). $J$ Clin Oncol. 2020;38(Suppl_15):5006. doi:10.1200/JCO.2020.38.15_suppl.5006

95. Choueiri TK, Kluger HM, George S, et al. FRACTION-RCC: innovative, high-throughput assessment of nivolumab + ipilimumab for treatment-refractory advanced renal cell carcinoma (aRCC). J Clin Oncol. 2020;38(Suppl_15):5007. doi:10.1200/ JCO.2020.38.15 suppl.5007

96. Choueiri TK, Albiges L, Powles T, et al. A phase 3 study (COSMIC-313) of cabozantinib in combination with nivolumab and ipilimumab in patients with previously untreated advanced renal cell carcinoma of intermediate or poor risk. Presented at: 2020 SITC Annual Meeting; November 9-14, 2020; Abstract 342.

97. Bekaii-Saab TS, Ou FS, Ahn DH, et al. Regorafenib dose-optimisation in patients with refractory metastatic colorectal cancer (ReDOS): a randomised, multicentre, open-label, phase 2 study. Lancet Oncol. 2019;20:1070-1082. doi:10.1016/S14702045(19)30272-4

98. Reiss KA, Yu S, Mamtani R, et al. Starting dose of sorafenib for the treatment of hepatocellular carcinoma: a retrospective, Multi-Institutional Study. J Clin Oncol. 2017;35:3575-3581. doi:10.1200/JCO.2017.73.8245

99. Iavarone M, Cabibbo G, Piscaglia F, et al. Field-practice study of sorafenib therapy for hepatocellular carcinoma: a prospective multicenter study in Italy. Hepatology. 2011;54:2055-2063. doi:10.1002/hep. 24644

100. Facciorusso A, Abd El Aziz MA, Sacco R. Efficacy of regorafenib in hepatocellular carcinoma patients: a systematic review and meta-analysis. Cancers (Basel). 2019;12:36. doi:10.3390/ cancers 12010036
Journal of Hepatocellular Carcinoma

\section{Publish your work in this journal}

The Journal of Hepatocellular Carcinoma is an international, peerreviewed, open access journal that offers a platform for the dissemination and study of clinical, translational and basic research findings in this rapidly developing field. Development in areas including, but not limited to, epidemiology, vaccination, hepatitis therapy, pathology

\section{Dovepress}

and molecular tumor classification and prognostication are al considered for publication. The manuscript management system is completely online and includes a very quick and fair peer-review system, which is all easy to use. Visit http://www.dovepress.com/ testimonials.php to read real quotes from published authors. 